\title{
POST-OPERATIVE WOUND INFECTIONS IN ELECTIVE SURGERIES- A STUDY AT GOVERNMENT GENERAL HOSPITAL, GUNTUR
}

\author{
Mudavatu Bhagavan Naik1, Meghavathu Govindu Naik², Rajesh P3
}

1 Professor, Department of Surgery, Guntur Medical College and Government General Hospital, Guntur, Andhra Pradesh. ${ }^{2}$ Assistant Professor, Department of Surgery, Guntur Medical College and Government General Hospital, Guntur, Andhra Pradesh. 3Junior Resident, Department of Surgery, Guntur Medical College and Government General Hospital, Guntur, Andhra Pradesh.

\section{ABSTRACT}

\section{BACKGROUND}

Surgical Site Infections (SSI) place a significant burden on both the patient and health system, prolongs hospital stay and adds to hospital costs.

\section{MATERIALS AND METHODS}

Patients were selected from general surgical ward with clean, clean contaminated wounds of major surgeries for this study for duration of 2 years from June 2015 to May 2017 at Government General Hospital, Guntur. Informed consent was taken from patients before they were enrolled for this study. Institutional ethical clearance has been obtained from the standard ethical committee.

\section{RESULTS}

Total patients studied were 100. In 89 cases wound healed by primary intention and in 11 cases had post-operative clinical as well as bacteriological wound sepsis. Out of 100 patients, 100 elective cases in which 11 cases were infected. Overall, wound infection rate was $11 \%$. There was increased incidence of post-operative wound infection in patients with following pre-disposing factorsDiabetes Mellitus, Peripheral Vascular Disease, Smoker and Alcoholic. Out of 38 clean wounds there were 4 infected cases (10.5\%) and out of 62 clean contaminated wounds 7 infected cases were present (11.3\%). This study showed the risk of post-operative wound infection is more in surgeries with longer duration.

\section{CONCLUSION}

The present study emphasised the complications associated with post-operative wound infections and identified the common factors responsible for post-operative wound infections and thus helped in modifying the approach in its management.

\section{KEY WORDS}

Surgical Site Infections (SSI), Incidence, Predisposing Factors, Post-Operative.

HOW TO CITE THIS ARTICLE: Naik MB, Naik MG, Rajesh P. Post-operative wound infections in elective surgeries- a study at government general hospital, Guntur. J. Evolution Med. Dent. Sci. 2018;7(21):2531-2533, DOI: 10.14260/jemds/2018/569

\section{BACKGROUND}

Infection is the clinical manifestation of the inflammatory reaction incited by invasion and proliferation of microorganisms. ${ }^{[1]}$ SSI places a significant burden on both the patient and health system,[2] thus prolongs hospital stay and adds to hospital costs.[3] The understanding of wound infection has come a long way from the days when pus was laudable. Far reaching advances in therapeutics, techniques in surgery and maintenance of asepsis have contributed to controlling scourge of surgery which is post-operative infection. Infection was accepted as an inevitable sequelae of surgery a century ago.

Although, a large number of reports on SSI are available in adult literature, ${ }^{[4-5]}$ reports for children are few and most are from developed countries with an overall incidence of $2.5 \%-20 \% \cdot[3,6-7]$

'Financial or Other Competing Interest': None.

Submission 13-04-2018, Peer Review 07-05-2018,

Acceptance 13-05-2018, Published 21-05-2018.

Corresponding Author:

Dr. M. Govindu Naik,

D. No. 85-6-422, 4th Lane,

Kodandaramaiah Nagar,

Lalapuram, Chuttugunta

Guntur-522004,

Andhra Pradesh.

E-mail:mgnaik009@yahoo.in

DOI: $10.14260 /$ jemds $/ 2018 / 569$
Although, the total elimination of wound infection is not possible, a reduction in the infection rate to a minimal level could have significant benefits in terms of both patient comfort and medical resources used.

Clear understanding of pathogens and their pathogenicity, advances in the field of asepsis and aseptic technique, the advent of antibiotics and reliable suture materials have furnished the surgical armamentarium in countering infection. Hence, a constant awareness of the ever present threat of infection must be a way of life for the entire surgical fraternity. In 1992, the surgical wound infection task force replaced the term 'Surgical Wound Infection' with 'Surgical Site Infection' - SSI.[8]

The main objective of the present study was to determine the incidence of post-operative wound infections and to identify the common pathogens causing surgical site infection from general surgical ward of Government General Hospital, Guntur.

\section{MATERIALS AND METHODS}

Patients were selected from general surgical ward with clean contaminated wounds of major surgeries for this study for duration of 2 years at Government General Hospital, Guntur from June 2015 to May 2017. Informed consent was taken from patients before they were enrolled for this study. 
Institutional ethical clearance has been obtained from the standard ethical committee.

\section{Study Design}

Prospective observational study.

\section{Inclusion Criteria}

Patients undergoing elective surgeries are included in this study. Patients of all age groups are categorised and included in the present study.

\section{Exclusion Criteria}

Patients with immune compromising diseases (eg: retroviral disease, tuberculosis etc.) are excluded from the present study.

\section{Collection and Transport of Pus}

Cotton swabs- 2 in number collected intraoperatively, one from subcutaneous tissue before wound closure and the other from the wound post-operatively when infection is suspected.

Special care was taken to avoid contaminating the specimen with commensal organisms from the skin as far as possible specimen from the wound was collected before antiseptic dressing was applied. Using sterile technique upto $5 \mathrm{~mL}$ of pus was collected from the drainage tube, which was transferred to a leak-proof sterile container. When pus is not being discharged, a sterile cotton-wool swab was used to collect the sample from infected site.

Special care was taken to send the specimen with a completed request form to reach the Microbiology laboratory within 6 hours.

One swab was used to make a smear of the material collected on clean slide for gram staining on day one. Other swab was used for culture. Media used for pus culture were blood agar and nutrient agar plates incubated for 24 hours aerobically. Isolates identified based on colony morphology and coagulation test. If culture turns out to be positive, then antibiotic sensitivity was performed (Muller-Hilton method).

\section{Statistical Analysis}

The details of all cases are summarised in the master chart and results of the study have been analysed in detail. Statistical analysis was done using Microsoft Excel 2010 version. Data was presented in percentages and proportions.

\section{RESULTS}

Total patients studied were 100. In 89 cases wound healed by primary intention and in 11 cases had post-operative clinical as well as bacteriological wound sepsis.

Out of 100 patients, 100 elective cases in which 11 cases were infected. Overall, wound infection rate was $11 \%$.

\section{Age Distribution}

In the present study, incidence of post-operative infections is directly proportionate to the age of patient. Higher the age, higher was the chances of infection. Out of the 6 cases $>60$ years of age, $33.3 \%$ developed infection compared to only one infected case out of 30 cases in $20-29$ years' age group (3.3\%).

\section{Sex Distribution}

No significant influence of sex in the incidence of wound infection. $12.2 \%$ of males $(n=4)$ had infected cases compared to $12 \%$ in females $(n=7)$.

\section{Predisposing Factors}

There was increased incidence of post-operative wound infection in patients with following predisposing factorsDiabetes Mellitus, Peripheral Vascular Disease, Smoker and Alcoholic

\begin{tabular}{|c|c|c|c|c|}
\hline $\begin{array}{c}\text { Sl. } \\
\text { No. }\end{array}$ & $\begin{array}{c}\text { Predisposing } \\
\text { Factors }\end{array}$ & $\begin{array}{c}\text { Total } \\
\text { Cases }\end{array}$ & $\begin{array}{c}\text { Infected } \\
\text { Cases }\end{array}$ & Percentage \\
\hline 1. & Diabetes Mellitus & 26 & 04 & $15.4 \%$ \\
\hline 2. & $\begin{array}{c}\text { Peripheral } \\
\text { Vascular Disease }\end{array}$ & 04 & 01 & $25 \%$ \\
\hline 3. & Smoker & 14 & 03 & $21.4 \%$ \\
\hline 4. & Alcoholic & 15 & 04 & $26.7 \%$ \\
\hline \multicolumn{4}{|c|}{ Table 1. Incidence of Infection in Patients with } \\
Predisposing Factors \\
\hline
\end{tabular}

\section{Type of Wound}

Out of 38 clean wounds there were 4 infected cases $(10.5 \%)$ and out of 62 clean contaminated wounds 7 infected cases were present $(11.3 \%)$.

\section{Rate of SSI in Elective Procedures}

Four cases of Appendicectomy, 3 cases of Hernia, 1 case of Gastric and 1 case of Biliary were infected cases.

\section{Duration of Surgery}

Duration of operation influencing the incidence of postoperative wound infection. The longer the duration of surgery the higher the chances of infection, as it was evident in the present study. 6 infected cases were seen in $>3$ hours of duration of surgery.

\section{Bacteriological Surveillance}

Among 11 cases of wound infection, gram negative bacilli were very often responsible for post-operative wound infection than gram positive organisms.

\begin{tabular}{|c|c|c|c|}
\hline Sl. No. & Name of Organism & Infected Case & Percentage \\
\hline 1. & Staphylococcus aureus & 4 & $36.3 \%$ \\
\hline 2. & Escherichia coli & 2 & $18.2 \%$ \\
\hline 3. & Klebsiella species & 1 & $9.1 \%$ \\
\hline 4. & Proteus species & 1 & $9.1 \%$ \\
\hline 5. & $\begin{array}{c}\text { Pseudomonas } \\
\text { aeruginosa }\end{array}$ & 1 & $9.1 \%$ \\
\hline 6. & $\begin{array}{c}\text { Beta-haemolytic } \\
\text { streptococci }\end{array}$ & 1 & $9.1 \%$ \\
\hline 7. & No pathogen grown & 1 & $9.1 \%$ \\
\hline
\end{tabular}

Table 2. Incidence of Individual Organism Isolated from Infected Wounds

In the present study gram positive organisms dominated among the isolated pathogenic organisms with Staphylococcus aureus about 36.3\% among the isolated organisms followed by E. coli $18.2 \%$, Klebsiella species $9.1 \%$, Proteus species 9.1\%, Pseudomonas 9.1\%, Beta-haemolytic streptococci $9.1 \%$ and no pathogens were isolated in about 9.1\% among infected patients. 


\section{DISCUSSION}

The Surgical Site Infection (SSI) is considered as one of the surgeon's nightmare 113 . This complication while seemingly infrequent and almost never lethal adds morbidity, delays incisional healing and thereby generates large marginal care expenses when measured in aggregate with an extra hospital stay of 6 - 14 days.[9]

The variability in estimates is consistent with the differences in the characteristics of the hospital populations, the underlying diseases, differences in clinical procedures, the extent of the infection control measures and in addition the hospital environment.

The overall infection rate in the present study is $11.12 \%$. Comparable with various other studies where the incidence ranged from $2.5 \%-41.9 \%, 123$ - 126 . This is due to poor nutritional status, inadequate infection controlling measures and inadequate diabetic control.

In the present study among the 100 patients operated, 11 patients had SSIs with an incidence of $11.12 \%$.

A study conducted by Kaya et al from University Hospital, Turkey in the year 2006 showed incidence of SSI's in 12.8\% of the operated patients.[10]

In the year 2009 a study conducted by Sangarasi AK et al from public sector medical university in Pakistan showed an incidence of $13 \%$ SSIs among the patients operated.[11]

A study conducted by Kamat US et al in a teaching hospital, Goa showed a very high incidence of $30.7 \%$ SSIs among the operated patients selected for study.[12]

The variability in the incidence accounts for intraoperative aseptic precautions, pre-operative comorbidities of the patient, post-operative nutritional status of the patient, post-operative nursing care and hospital environment.

In the present study surgical site infections, the incidence of clean, clean contaminated are $10.5 \%, 11.3 \%$ respectively.

Compared to the present study, study by Kaya et al,[10] Sangarasi et al[11] and Kamat et al[12] found an incidence of $3.4 \%$ and $9.2 \% ; 5.4 \%$ and $12.3 \% ; 5.4 \%$ and $35.5 \%$ clean and clean contaminated wounds respectively.

The high rate of infections in cases may be attributed to patient related factors like poor hygiene, lack of maintaining proper cleanliness and hospital related factors like inappropriate techniques of maintaining dressings, hospital cleanliness and hospital acquired infections.

SSIs are an important cause of increased hospital stay, and they directly affect the morbidity and risk of mortality of surgical patients, particularly older patients.[12]

This topic is chosen for study since surgical site infection (SSIs) are the second most common cause of nosocomial infections. Upto $2 \%$ - $5 \%$ of patients undergoing clean extraabdominal operations and upto $20 \%$ undergoing intraabdominal operations will develop surgical site infection.

\section{CONCLUSION}

The incidence of post-operative wound infection in this study was $11.12 \%$ and the incidence of SSI was more in clean contaminated cases with an incidence of $11.3 \%$. This study showed the risk of post-operative wound infection is more in surgeries with longer duration.
Patients with co-morbid conditions and predisposing factors had higher incidence of post-operative wound infection. In this study patients with age more than 60 years had an incidence of $33.3 \%$, which was considerably high compared to other age groups in the study.

Most common pathogens identified were gram positives, out of which staphylococcus aureus had the highest incidence of $36.4 \%$. The present study emphasised the complications associated with post-operative wound infections and identified the common factors responsible for post-operative wound infections and thus helped in modifying the approach in its management.

\section{REFERENCES}

[1] Mollit D. Surgical infections. In: Ziegler MA. Operative pediatric surgery. McGraw-Hill, 2003:61-78.

[2] Wilson AP, Gibbons C, Reeves BC, et al. Surgical wound infection as a performance indicator: agreement of common definitions of wound infection in 4773 patients. BMJ 2004;329(7468):720.

[3] Horwitz JR, Chwals WJ, Doski JJ, et al. Pediatric wound infections: a prospective multicenter study. Ann Surg 1998;227(4):553-8.

[4] Efem SEE, Aja A, Inyang U. Surgical wound infection rate in Calabar University Teaching Hospital, Calabar. West Afr J Med 1986;5:61-8.

[5] Ojiegbe GC, Njoku-Obi AN, Ojukwu JO. Incidence and parametric determinants of post operative wound infections in a university teaching hospital. Cent Afr J Med 1990;36(3):63-7.

[6] Bhattacharyya N, Kosloske AM. Postoperative wound infection in pediatric surgical patients: a study of 676 infants and children. J Pediatr Surg 1990;25(1):125-9.

[7] Uludag 0 , Rieu P, Niessen M, et al. Incidence of surgical site infections in pediatric patients: a 3-month prospective study in an academic pediatric surgical unit. Pediatr Surg Int 2000;16(5-6):417-20.

[8] Horan TC, Gaynes RP, Martone WJ, et al. CDC definitions of nosocomial surgical site infections, 1992: a modification of CDC definitions of surgical wound infections. Infect Control Hosp Epidemiol 1992;13(10):606-8.

[9] Mack RM, Cantrell JR. Quantitative studies of bacterial flora on open skin wounds: the effects of topical antibiotics. Ann Surg 1967;166(6):886-95.

[10] Kaya E, Yetim I, Dervisoglu A, et al. Risk factors for and effect of a one year surveillance programme on surgical site infection at a University Hospital in Turkey. Journal of Surgical Infections 2006;7(6):51926.

[11] Sangrasi AK, Leghari AA, Memon A, et al. Surgical site infection rate and associated risk factors in elective general surgery at a public sector medical university in Pakistan. Int Wound J 2008;5(1):74-8.

[12] Kamat US, Fereirra AM, Kulkarni MS, et al. A prospective study of surgical site infections in a teaching hospital in Goa. Indian J Surg 2008;70(3):120-4. 